\title{
Life and Health on the Edge
}

HERE ON THE BLUE PLANET we tend to live life on the edge. Throughout nature, edges are places where great things, the good with the bad, tend to happen. From time immemorial, humans have especially favored the edge where land and ocean meet in a productive and sometimes turbulent coexistence. Situated at its privileged edge, one astronomical unit from the sun, the ocean gives us our life-sustaining atmosphere, redistributes incident solar energy so that we thrive in an overall temperate climate, and is the fount of rain and freshwater for ecosystems and human societies far from the edge of the sea. For centuries, explorers, poets, and the starving have sojourned at the edge looking out to sea for answers.

For hundreds of millions of people worldwide, the ocean is the cornucopia for quality of life and health, a highway for commerce and travel, a wonderland with a seemingly endless variety of recreational and creative possibilities, and a source of livelihood. With increasing difficulty and seemingly miraculously, the sea continues to yield fish, the major source of protein for the human diet. Over the past one hundred years of exploration, we have discovered at an accelerating pace that the ocean provides other resources that can be used to advance biomedical research, cure or ameliorate human disease, and save lives. Today, when the development of new drugs is in a dead heat with evolving antibiotic-resistant human pathogens, we are looking with renewed interest to the ocean, the world's most enduring ecosystem, for the elixirs that make health and long life possible amid an ever-evolving milieu of parasites and predators.

But living by the sea, feasting upon its bounty, and venturing into it in search of its treasures has always meant that we prospect at an edge where gaining ac- cess to the life- and health-giving resources of the sea inevitably involves risks that we must understand so that they can be predicted and minimized or eliminated altogether. To protect our marine food resources and the coastal waters in which we play and work we must understand the fundamental mechanisms leading to harmful algal blooms and the dynamics of human pathogens in the coastal marine system. The tragedies of December 2004 in the Indian Ocean and September 2005 in the Gulf of Mexico demonstrate that there is much room for improvement in our understanding of tsunamis and marine storms. Whether we live in a developing island nation or in the richest country in the world, we all live on the edge when we interact with the sea.

In this special issue of Oceanography, some thirty scientists working at the cutting edge of discovery in the nascent field of "the oceans and human health" provide an overview of recent progress in our understanding of the health risks and benefits of life on the edge. They provide insight into the budding of a new research field and their own first baby steps in the building of a new kind of multidisciplinary research community organized for the sake of scientific progress and the alleviation of human suffering. More importantly, they offer us a vision of what may lie ahead-beyond the edge.

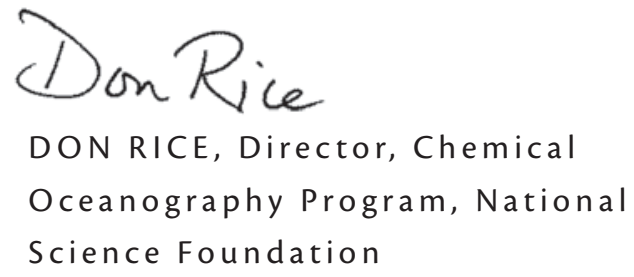

